\title{
Observation and parameterization of small icebergs: Drifting breakwaters in the southern ocean
}

\author{
Fabrice Ardhuin $^{a}{ }^{a}$, , Jean Tournadre ${ }^{a}$, Pierre Queffeulou ${ }^{a}$, Fanny Girard-Ardhuin ${ }^{a}$, Fabrice Collard ${ }^{b}$ \\ a Ifremer, Laboratoire d'Océanographie Spatiale, Brest, France \\ ${ }^{\mathrm{b}}$ Division Radar, Collecte Localisation Satellites, Plouzané, France \\ *: Corresponding author : Fabrice Ardhuin, email address : ardhuin@ifremer.fr
}

\begin{abstract}
:
The variability of small-size iceberg distributions is revealed from a novel analysis of satellite altimeter data. A strong annual cycle is modulated by pulse-like events confined to single ocean basins, with dense iceberg populations in the South Atlantic in 2004-2005, and in the South Pacific in 2008. Anomalies in sea surface temperatures of the order of $1{ }^{\circ} \mathrm{C}$ may be related to the iceberg distribution. Icebergs also appear very strongly associated with anomalies in the heights of ocean waves. A preliminary parameterization of wave blocking by icebergs significantly reduces wave model errors in the region south of $45^{\circ}$ South, and has a perceptible influence on all the west coasts of the Southern hemisphere.
\end{abstract}

\section{Highlights}

- The distribution of small icebergs in the Southern Ocean was fully mapped for the first time, thanks to a novel technique. The distribution of icebers is quite variable. Icebergs have a strong impact on ocean waves. A parameterization of icebergs provides a much improved wave model for the Southern Ocean. Iceberg effects can be seen (through swells) a few thousands of kilometers away.

Keywords : Iceberg ; Waves

\section{Introduction}

The distribution of icebergs less than $6 \mathrm{~km}$ in length, has been known from ship-based observations [e.g. 22, 8], and synthetic aperture radar analyses [23]. Both techniques have only been applied on limited time and spatial scales. These small icebergs may account for a significant part of the freshwater volume flux delivered by icebergs to the Southern Ocean [15], with an associated iron flux important for the ocean primary productivity [16]. Icebergs also pose a consid- erable threat to navigation. Besides, although there is an abundant literature on the complex topic of wave interactions with sea ice [e.g. 17, 10,11], there is little published investigation of the response of icebergs to wave motion [e.g. 7], and even less on the consequences for the wave field.

Recently, [21] demonstrated that small icebergs, with areas in the range 0.5 to $30 \mathrm{~km} 2$, have a significant signature in the noise part of high resolution altimeter waveforms, that can be analyzed to determine their distribution. Here we present the first climatology of small icebergs for the entire Southern ocean, and analyze its relationship with other observations, in particular ocean wave heights. We show here that icebergs have a strong impact on ocean waves at the scale of the entire Southern Ocean and should be parameterized to achieve more accurate wave forecasts. We prove here that a lack of iceberg parameterization 
Figure 1: (a) Normalized distribution of iceberg areas detected using Jason-1 altimeter data, for the year 2004. The dashed line shows a fit of the histogram used for numerical wave modeling. (b) Schematic of damping of waves by icebergs of identical areas but different shapes and orientations. The amplitude of the wave is represented by the contrast in gray level of the background stripes.

appears to be the main limiting factor for the accuracy of present state-of-the-art ocean wave models in that region.

\section{Analysis}

Besides the detection of icebergs, the analysis of altimeter waveforms also provides the icebergs freeboard $h$ (elevation above sea level), while the iceberg area $A$ is related to the radar backscatter strength [21]. The Jason-1 altimeter archive, from 2002 to 2008, has been processed to produce a database of small icebergs over the southern Ocean (south of $45^{\circ} \mathrm{S}$ ). Jason-2 data provides an extension to the present with similar quality.

Because the coverage of the ocean by a single satellite is limited to a narrow swath, about $6-8 \mathrm{~km}$ wide, the we integrate the data to estimate the probability $P$ of presence of an iceberg, with a time and space resolutions of 1 month and $100 \mathrm{~km}$ respectively. Given the low variability of $P$, from one month to the next, this estimate of $P$ is probably reliable. That resolution is close to the Jason-1 track spacing at $50^{\circ}$ latitude, which has a 10 day repeat cycle. This probability is estimated by the number of altimeter samples which contain one iceberg divided by the number of good altimeter samples. The number of Jason passes increased markedly towards the high latitudes, providing more robust iceberg statistics. We estimate ice volumes from iceberg areas, assuming that $90 \%$ of the volume is underwater, which may be overestimated by a few percents,

$$
V(i, j, t)=10 P(i, j, t) A(i, j, t) h(i, j, t) \frac{\Delta x \Delta y}{A_{S W}}
$$

with $A(i, j, t)$ the average iceberg area, $(\Delta x, \Delta y)$ the sampling grid spacing and $A_{S W}$ the area of the altimeter field of view. The histogram of iceberg sizes for the entire Southern ocean and all the year 2004 is shown in figure 1,a. The altimeter is not expected to properly detect all icebergs with areas less than $0.5 \mathrm{~km}^{2}$. Although the missed small icebergs contribute little to the ice volume, they may still have a significant effect on the propagation of ocean waves. Our extrapolation if the iceberg distribution to smaller sizes is broadly consistent with published size distributions by [?] and [22]. Figure 1]b illustrates how elongated icebergs can produce a larger shadow than square icebergs. The analysis of a few synthetic aperture radar (SAR) scenes confirm that icebergs, like any floating body, tend to align with their length along the wave crests, and can produce a strong attenuation when wave heights are analyzed using well 
Figure 2: Example of a synthetic aperture image acquired by Envisat's ASAR instrument at $53^{\circ} \mathrm{S} 155^{\circ} \mathrm{W}$ on December 26, 2008, 9:35 UTC. White areas are the sides of icebergs facing the satellite. Waves propagate from the West (left of the image, see arrow) and a majority of icebergs align their longer sides in the North-South direction. The dark areas to the right of bright spots are either the body of iceberg in or the sea surface in the radar shadow behind the iceberg (narrow strips next to the iceberg), or areas with low wind and/or greasy ice for which the backscatter is very low. A few icebergs are almost square tabular bergs with their top seen in an intermediate grey level between the very bright illuminated sides and the darker modulated sea. The "short" modulations (with a $270 \mathrm{~m}$ wavelength) in the grey level throughout the image are the ocean waves. Only $25 \%$ of the full image is shown.

established SAR modulation transfer functions [5]. In the radar scene shown in figure 2, the peak wavelength is $270 \mathrm{~m}$, which corresponds to a $13 \mathrm{~s}$ wave period, and the wave height decreases from 2.7 to $1.8 \mathrm{~m}$ over $140 \mathrm{~km}$.

\section{Results}

Integrating the iceberg volume in the open ocean (outside of sea ice) from $65^{\circ} \mathrm{S}$ to $45^{\circ} \mathrm{S}$, the outstanding pattern revealed by Figure 3 , is the predominance of the South Atlantic sector $\left(50^{\circ} \mathrm{W}\right.$ to $\left.30^{\circ} \mathrm{E}\right)$ with most small icebergs formed in the Weddell sea during the austral summer. In that sector, the ice volume can exceed $100 \mathrm{Gt}$ (Figure 3,d), and a large amount of ice reaches as far as $45^{\circ} \mathrm{S}$ in late 2003 (Figure 4 a). These volumes are not negligible compared to the $1100 \mathrm{Gt}$ annual mass flux estimated for giant icebergs [With lengths greater than $18.5 \mathrm{~km}[15]$. Besides, small icebergs are probably mostly created by the break-up of larger tabular bergs, and their location should be closely correlated. The year to year variation of the ice volume is important, with bursts of iceberg formation occurring in 2004-2005 in the South Atlantic, and in 2008 in the Ross sea. A strong negative anomaly in sea water temperature is found around large concentrations of icebergs, in the South Pacific in 2008, and South Atlantic in 2004-2005 (Figure 3,b). Although not systematic, these patterns can be caused by iceberg melting, which, previously, could only be inferred from runoff estimates for Antarctica and a modeling of iceberg drift [e.g. 6] .

The errors of a numerical wave model that does not account for icebergs, provides an independent verification of our iceberg detection. This wave model is based on the WAVEWATCH III ${ }^{\circledR}$ code [20] and forced by analysed winds and sea ice mask from ECMWF, treated with the subgrid method by [19]. Both forcing and model have a resolution of $0.5^{\circ}$ in longitude and latitude. The model without iceberg effects is described by [9], using the TEST441b parameterization proposed by [2] and further described in [3]. This parameterizations includes, in particular, a non-linear swell dissipation based on the observations of longrange swell decay [1]. This model generally provides very accurate estimate of sea states without any assimilation of wave data [4]. Model results for the significant wave height $H_{s}$ are compared with observations derived from all 
Figure 3: Longitude-time Hovmöller diagrams of (a) the total volume of small icebergs between latitudes $65^{\circ} \mathrm{S}$ and $45^{\circ} \mathrm{S}$, over a $2^{\circ}$ sector in longitude, (b) sea surface temperature anomaly estimated using the weekly NOAA Optimum Interpolation Sea Surface Temperature Version2 [14]). (c) Biases of modeled significant wave heights [3] relative to satellite altimeter measurements [12]. (d) Total volume of small icebergs from the whole southern ocean (green), and the south Atlantic ocean $\left(50^{\circ} \mathrm{W}\right.$ to $30^{\circ} \mathrm{E}$, black), south Indian ocean $\left(50^{\circ} \mathrm{E}\right.$ to $130^{\circ} \mathrm{E}$ red) and South Pacific ocean $\left(130^{\circ} \mathrm{E}\right.$ to $100^{\circ} \mathrm{W}$, red).

available satellite altimeters (typically Jason, ENVISAT and Geosat FOllow On), as calibrated by [12]. This comparison is based on values averaged alongtrack over 1 degree in latitude [13].

Model biases are less than $30 \mathrm{~cm}$ except for latitudes $65^{\circ} \mathrm{S}$ to $45^{\circ} \mathrm{S}$, where the positive bias pattern is very similar to iceberg concentrations, with the same strong space-time variability. The bias pattern is shifted by 5 to $10^{\circ}$ to the East of the iceberg distribution (Figure 3.c). This shift is consistent with the expected partial blocking of the wave energy flux, predominantly oriented eastward. Namely, the model that does not account for icebergs is overestimating the wave heights in the regions that are, in reality, sheltered by the icebergs. The general negative bias in 2002 is related to stronger negative biases in modeled winds before 2003. Given the impact of waves on nearshore and upper ocean mixing, large gradients in wave height at the scale of individual icebergs probably enhance the mixing of water properties, while the icebergs also induce wind-driven upwelling.

Beyond these local effects of icebergs on the sea state, the errors in modeled significant wave height also appear to propagate further North, beyond the regions covered with icebergs (figures 3.d,e,f).

\section{Wave modeling with icebergs}

In order to understand this remote effect, we defined a first simple parameterization of the icebergs as moving sub-grid obstacles, following the treatment of (fixed) subgrid islands and (moving) marginal ice by [19]. Neglecting diffraction effects that are probably important in practice, in particular for the smaller icebergs as it is the case for ice floes [e.g. 11], we assume that icebergs are square and completely absorb the wave energy flux that they intercept. We define the proportion $r$ of the incoming wave energy flux blocked by icebergs over a unit propagation distance ( here $1 \mathrm{~km}$ ) is the length of the icebergs, in the direction perpendicular to the propagation, per unit propagation distance. For an individual rectangular iceberg perpendicular to the wave propagation direction, the iceberg area is this length multiplied by a width (Figure 1.b).

For a not too dense population of icebergs or for a short propagation distance, we may neglect the probability that two icebergs may be aligned in the wave propagation direction, and $r$ is given by the ratio

$$
r(i, j, t)=C(i, j, t) / W(i, j, t)
$$


Figure 4: Latitude-time Hovmöller diagrams of the small iceberg ice volume over each $2^{\circ}$ band of latitude for (a) the South Atlantic $50^{\circ} \mathrm{W}$ to $30^{\circ} \mathrm{E}$, (b) the Indian Ocean $50^{\circ} \mathrm{E}$ to $130^{\circ}$ E, (c) the South Pacific $130^{\circ} \mathrm{E}$ to $100^{\circ}$ W. (d), (e), and (f) significant wave height model bias against satellite altimeters for the same three sectors of the Southern Ocean, for a model without iceberg effects. In the left panels $(a, b, c)$ the black line marks the annual maximum extent of the sea ice, and in the right panels $(\mathrm{d}, \mathrm{e}, \mathrm{f})$ the white areas give the minimum extent of the $80 \%$ sea ice coverage, used as a mask in the model.

of the fraction of sea area covered by icebergs,

$$
C(i, j, t)=P(i, j, t) \frac{A(i, j, t)}{A_{S W}}
$$

and an effective iceberg width in the wave propagation direction

$$
W=\sum_{k} C_{0}(k) A_{0}(k) / \sum_{k} C_{0}(k) \sqrt{A_{0}(k)}
$$

where $k$ is the iceberg size index, and $C_{0}(k)$ is the number of icebergs of area $A_{0}(k)$. Here $C_{0}$ was taken uniform in space and time, i.e. independent of

Figure 5: Impact of iceberg in model errors for the significant wave height $H_{s}$. The top panel shows the model normalized root mean square error against altimeter measurements of $H_{s}$, for the year 2008. This is similar to figure 11 in 3]. The middle panel show the same error measure for a model that includes a representation of icebergs. Contours are drawn for 7.5, $10,12.5,15$ and $20 \%$ error levels. The bottom panel show the maximum difference, in meters, over the year 2008 , between modeled wave heights without $\left(H s_{1}\right)$ and with $\left(H s_{2}\right)$ icebergs.

$i, j$ and $t$. As a result $W$ is a constant that only depends on the iceberg size histogram. Provided that icebergs do occur in groups that align preferentially in a particular direction relative to the dominant wave direction, the wave decay is exponential, with a spatial rate $r$ that has units of $\mathrm{km}^{-1}$. In the model, the energy flux at each grid point is reduced by $\exp (r \Delta)$, where $\Delta$ is the grid spacing in kilometers.

The fitted size distribution shown in figure 1 gives $W=0.85 \mathrm{~km}$. Here $C(i, j, t)$ reaches as much as $1.2 \%$, corresponding to a decay $r=0.02 \mathrm{~km}^{-1}$, or an e-folding scale $1 / r$ of $50 \mathrm{~km}$. This scale is very short compared to the growth scale of waves in strong winds which is of the order of 300 to $1000 \mathrm{~km}$ [18]. More typical values $r \simeq 0.002 \mathrm{~km}^{-1}$ give attenuation scales comparable to the wind-wave growth scales.

If the histogram were restricted to icebergs larger than $0.5 \mathrm{~km}^{2}$, we would get an effective iceberg width $W=1.6 \mathrm{~km}$ (in the direction of wave propagation), and, according to eq. (21), a weaker effect on waves. This illustrates the importance of the smallest icebergs, which should still have lengths larger than 
the dominant wavelength of wind-waves, i.e. a few hundred meters, to have any strong blocking effect.

Here we show model results obtained with $W$ set to $0.42 \mathrm{~km}$. This reduction of $W$, which increases the local iceberg effect by a factor of two, was first motivated by the fact that it gave a slightly better result in terms of wave heights. Why the model fits the data better for $W<0.8 \mathrm{~km}$ is likely the result of the geometry of the icebergs that are not square. From the analysis of a few synthetic aperture radar images [see also 23], small icebergs appear to have their longer side perpendicular to the wave direction (figure 21), which is why we termed length the dimension is that direction. A smaller $W$ can also be the result of a varying size histogram with, in reality, a larger proportion of small icebergs away from the Antarctic continent.

Figure 6: Bias of modeled significant wave heights relative to satellite altimeter measurements without (left) and with (right) iceberg parameterization, for strips of ocean with a $2^{\circ}$ width in longitude and extending from $65^{\circ} \mathrm{S}$ to $45^{\circ} \mathrm{S}$. The processing is identical to what was done to obtain figure $3 \mathrm{c}$, with the addition of the year 2009 for which iceberg data was processed from Jason-2 and without the year 2002 for which the wave model is less accurate due to less accurate wind fields.

The wave model is validated with measurements of wave height from all altimeters (in the case of figure 5, these are Jason-1, ENVISAT and GFO), which, given the low probability of iceberg detection, are practically independent from the Jason-derived iceberg data. Including the parametrization for icebergs in the wave model, reduces all the large positive biases shown in Figure 3. c, up to $1.13 \mathrm{~m}$ for $H_{s}$, to less than $0.58 \mathrm{~m}$ (figure6). Although the model error is also due to errors in the driving winds and sea ice mask and parameterization errors, the large biases in the model without icebergs are anomalous. Considering the ocean south of $40^{\circ}$ South, the root mean square model bias over $2^{\circ}$ bands in longitude is $0.1 \mathrm{~m}$. For the months and longitudes for which biases exceeds twice this standard deviation, which may be considered as the model noise level, the addition of icebergs produces an average reduction in bias from $0.32 \mathrm{~m}$ to $0.2 \mathrm{~m}$.

Not only the biases but also the random errors are reduced in the upgraded model. For the year 2008 (Figure 5), the normalized root mean square error (NRMSE) is lowered by $12 \%$ for all the region South of $45^{\circ} \mathrm{S}$. This includes a clear improvement ( $10 \%$ reduction in error) of the model results along all the South-American continent due to a better representation of swells propagated from the Southern ocean.

For a single wave event, icebergs at $60^{\circ}$ South may, according to the model, reduce wave heights by $20 \mathrm{~cm}$ as far as $10^{\circ}$ South (figure 5. c). This improved variability of the model, with a very limited change in the mean wave heights $(2 \%$ reduction over the ocean south of $45^{\circ} \mathrm{S}$ ) provides a solid verification of the reality of the iceberg population patterns derived from the altimeter data. Similar results are found for other years, with stronger impacts in 2004. All these model results and the iceberg masks are available from http://tinyurl.com/yetsofy. 


\section{Conclusion}

The global iceberg database presented here reveals an annual cycle with a large inter-annual variability. These icebergs are related to large anomalies in sea surface temperatures and they also strongly impact ocean waves, with a far-reaching impact. This was illustrated with the iceberg blocking influence on swells in the Pacific, that affects the South American coasts. At the scale of the Southern Ocean, iceberg distribution patterns was found to be strongly correlated with wave model errors. A first parameterization of wave blocking by the icebergs removed the largest errors in the model. Yet, the model is based on an empirical iceberg shape factor that calls for further validation at smaller scales. Although we found no clear relationship between iceberg bursts and ocean color anomalies, as expected from [e.g. 16], the present findings call for a continued monitoring of icebergs and their associated freshwater and nutrient flux to the Southern Ocean. For this, altimeter data is complementary to synthetic aperture radar data that is best used for calibration on limited areas, due to the large volume of acquisitions and processing required. Now that CNES and NOAA make the Jason-2 waveforms available in near real time (delay of a few hours), it is also possible to use the latest data to define an iceberg mask usable for wave forecasts. This shall be attempted shortly.

Acknowledgments. F.A. is funded by ERC grant \#240009 "IOWAGA" and U.S. National Ocean Partnership Program, under grant N00014-10-1-0383. Altimeter data from Jason-1 and Jason-2 was kindly provided by CNES and NOAA through AVISO and NOAA/NODC. SAR imagery was kindly provided by ESA.

\section{References}

[1] Ardhuin, F., Chapron, B., Collard, F., 2009. Observation of swell dissipation across oceans. Geophys. Res. Lett. 36, L06607.

[2] Ardhuin, F., Marié, L., Rascle, N., Forget, P., Roland, A., 2009. Observation and estimation of Lagrangian, Stokes and Eulerian currents induced by wind and waves at the sea surface. J. Phys. Oceanogr. 39 (11), $2820-2838$.

URL http://ams .allenpress.com/archive/2541-2558/39/11/pdf/i1520-0485-39-11-2820.pdf

[3] Ardhuin, F., Rogers, E., Babanin, A., Filipot, J.-F., Magne, R., Roland, A., van der Westhuysen, A., Queffeulou, P., Lefevre, J.-M., Aouf, L., Collard, F., 2010. Semi-empirical dissipation source functions for wind-wave models: part I, definition, calibration and validation. J. Phys. Oceanogr. 40 (9), 1917-1941.

[4] Bidlot, J.-R., 2008. Intercomparison of operational wave forecasting systems against buoys: data from ECMWF, MetOffice, FNMOC, NCEP, DWD, BoM, SHOM and JMA, September 2008 to November 2008. Tech. rep., Joint WMO-IOC Technical Commission for Oceanography 
and Marine Meteorology, available from http://preview.tinyurl.com/7bz6jj. URL http://www.jcomm-services.org/modules/documents/documents/model_comparison_second_l

[5] Collard, F., Ardhuin, F., Chapron, B., 2005. Extraction of coastal ocean wave fields from SAR images. IEEE J. Oceanic Eng. 30 (3), 526-533.

[6] Gladstone, R. M., Bigg, G. R., Nicholls, K. W., 2001. Iceberg trajectory modeling and meltwater injection in the Southern Ocean. J. Geophys. Res. 106 (C9), 19,903-19,915.

[7] Goodman, D. J., Wadhams, P., Squire, V. A., 1980. The flexural response of a tabular ice island to ocean swell. Annals of Glaciology 1, 23-27.

[8] Jacka, T. H., Giles, A. B., 2006. Antarctic iceberg distribution and dissolution from ship-based observations. J. Glaciol. 53, 341-356.

[9] Magne, R., Ardhuin, F., Roland, A., 2010. Prévisions et rejeux des états de mer du globe à la plage (waves forecast and hincast from global ocean to the beach). European Journal of Environmental and Civil Engineering $14,149-162$.

[10] Meylan, M., Squire, V., Fox, C., 1997. Towards realism in modeling ocean wave behavior in marginal ice zones. J. Geophys. Res. 102 (C10), 2298122991.

[11] Meylan, M. H., 2002. The wave response of ice floes of arbitrary geometry. J. Geophys. Res. 107 (C1), 3005.

[12] Queffeulou, P., Croizé-Fillon, D., 2010. Global altimeter SWH data set, version 7, may 2010. Tech. rep., Ifremer, uRL:http://tinyurl.com/2cj5sez. URL ftp://ftp.ifremer.fr/ifremer/cersat/products/swath/altimeters/waves/documentation/a

[13] Rascle, N., Ardhuin, F., Queffeulou, P., Croizé-Fillon, D., 2008. A global wave parameter database for geophysical applications. part 1: wave-current-turbulence interaction parameters for the open ocean based on traditional parameterizations. Ocean Modelling 25, 154-171, doi:10.1016/j.ocemod.2008.07.006.

URL http://hal .archives-ouvertes.fr/hal-00201380/

[14] Reynolds, R. W., Rayner, N., Smith, T., Stokes, D., Wang, W., 2002. An improved in situ and satellite SST analysis for climate. J. Climate 15, $1609-1625$.

[15] Silva, T. A. M., Bigg, G. R., Nicholls, K. W., 2006. Contribution of giant icebergs to the southern ocean freshwater flux. J. Geophys. Res. 111, C03004.

[16] Smith, Jr., K. L., Robison, B. H., Helly, J. J., Kaufmann, R. S., Ruhl, H. A., Shaw, T. J., Twining, B. S., Vernet, M., 2007. Free-drifting icebergs: Hot spots of chemical and biological enrichment in the Weddell sea. Science 317, $478-482$. 
[17] Squire, V., Duggan, J., Wadhams, P., Rottier, P., Liu, A., 1995. Of ocean waves and sea ice. Annu. Rev. Fluid Mech. 27 (3), 115-168.

[18] Sverdrup, H. U., Munk, W. H., 1947. Wind, sea, and swell: theory of relations for forecasting. Tech. Rep. 601, U. S. Hydrographic Office.

[19] Tolman, H. L., 2003. Treatment of unresolved islands and ice in wind wave models. Ocean Modelling 5, 219-231.

[20] Tolman, H. L., 2008. A mosaic approach to wind wave modeling. Ocean Modelling 25, 35-47.

[21] Tournadre, J., Whitmer, K., Girard-Ardhuin, F., 2008. Iceberg detection in open water by altimeter waveform analysis. J. Geophys. Res. 113 (7), C08040.

[22] Wadhams, P., 1988. Winter observations of iceberg frequencies and sizes in the south atlantic ocean. J. Geophys. Res. 93, 3583-3590.

[23] Williams, R. N., Rees, W. G., Young, N. W., 1999. A technique for the identification and analysis of icebergs in synthetic aperture radar images of Antarctica. Int. J. Remote Sensing 20 (15), 3183-3199. 


\section{Figures}

Figure 1.

(a) Normalized distribution of iceberg areas detected using Jason-1 altimeter data, for the year 2004. The dashed line shows a fit of the histogram used for numerical wave modeling. (b) Schematic of damping of waves by icebergs of identical areas but different shapes and orientations. The amplitude of the wave is represented by the contrast in gray level of the background stripes.
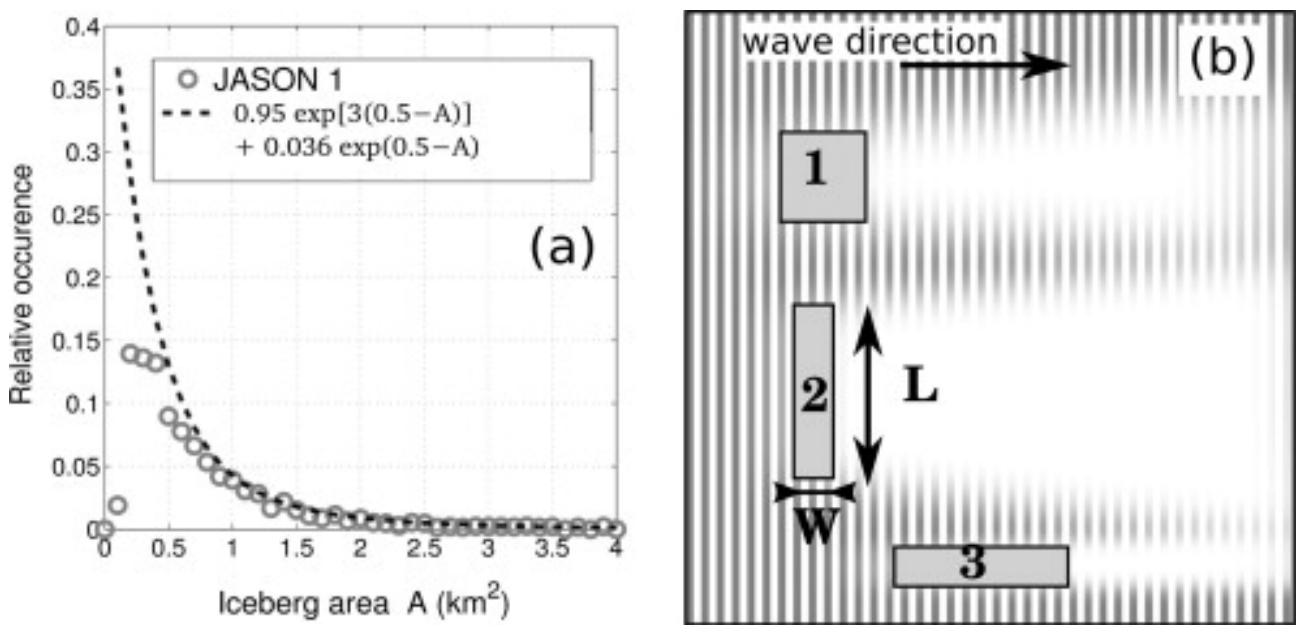


\section{Figure 2}

Example of a synthetic aperture image acquired by Envisat's ASAR instrument at $53^{\circ} \mathrm{S}$ $155^{\circ} \mathrm{W}$ on December 26, 2008, 9:35 UTC. White areas are the sides of icebergs facing the satellite. Waves propagate from the West (left of the image, see arrow) and a majority of icebergs align their longer sides in the North-South direction. The dark areas to the right of bright spots are either the body of icebergs or the sea surface in the radar shadow behind the iceberg (narrow strips next to the iceberg), or areas with low wind and/or greasy ice for which the backscatter is very low. A few icebergs are almost square tabular bergs with their top seen in an intermediate grey level between the very bright illuminated sides and the darker modulated sea. The "short" modulations (with a $270 \mathrm{~m}$ wavelength) in the grey level throughout the image are the ocean waves. Only $25 \%$ of the full image is shown.

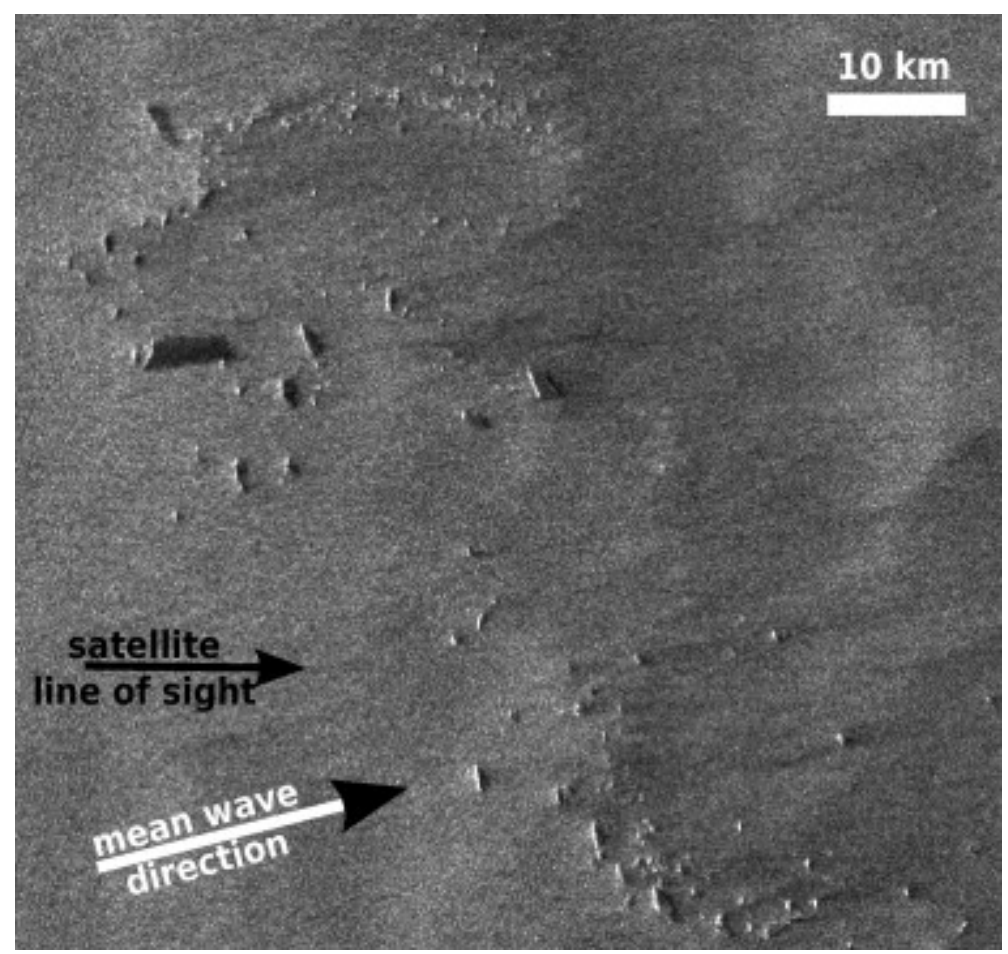


Figure 3

Longitude-time Hovmöller diagrams of (a) the total volume of small icebergs between latitudes $65^{\circ} \mathrm{S}$ and $45^{\circ} \mathrm{S}$, over a $2^{\circ}$ sector in longitude, (b) sea surface temperature anomaly estimated using the weekly NOAA Optimum Interpolation Sea Surface Temperature Version2 (Reynolds et al., 2002). (c) Biases of modeled significant wave heights (Ardhuin et al., 2010) relative to satellite altimeter measurements (Queffeulou and Croizé-Fillon, 2010). (d) Total volume of small icebergs from the whole southern ocean (green), and the south Atlantic ocean $\left(50^{\circ} \mathrm{W}-30^{\circ} \mathrm{E}\right.$, black), south Indian ocean $\left(50^{\circ} \mathrm{E}-130^{\circ} \mathrm{E}\right.$ red) and South Pacific ocean $\left(130^{\circ} \mathrm{E}-100^{\circ} \mathrm{W}\right.$, blue). (For interpretation of the references to color in this figure legend, the reader is referred to the web version of this article.)

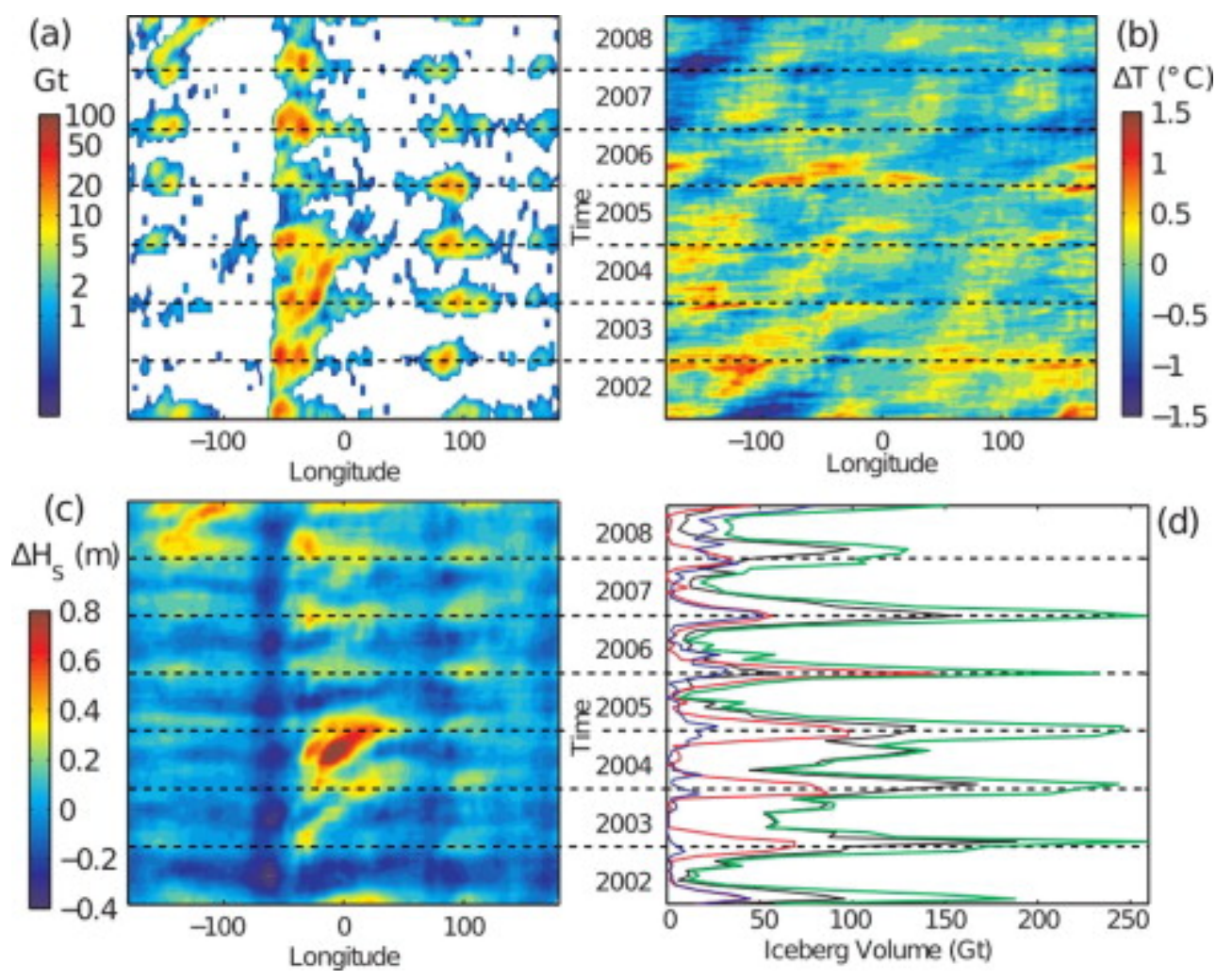


Figure 4

Latitude-time Hovmöller diagrams of the small iceberg ice volume over each $2^{\circ}$ band of latitude for (a) the South Atlantic $50^{\circ} \mathrm{W}-30^{\circ} \mathrm{E}$, (b) the Indian Ocean $50^{\circ} \mathrm{E}-130^{\circ} \mathrm{E}$, (c) the South Pacific $130^{\circ} \mathrm{E}-100^{\circ} \mathrm{W}$. (d)-(f) significant wave height model bias against satellite altimeters for the same three sectors of the Southern Ocean, for a model without iceberg effects. In the left panels $(\mathrm{a}-\mathrm{c})$ the black line marks the annual maximum extent of the sea ice, and in the right panels $(d-f)$ the white areas give the minimum extent of the $80 \%$ sea ice coverage, used as a mask in the model.

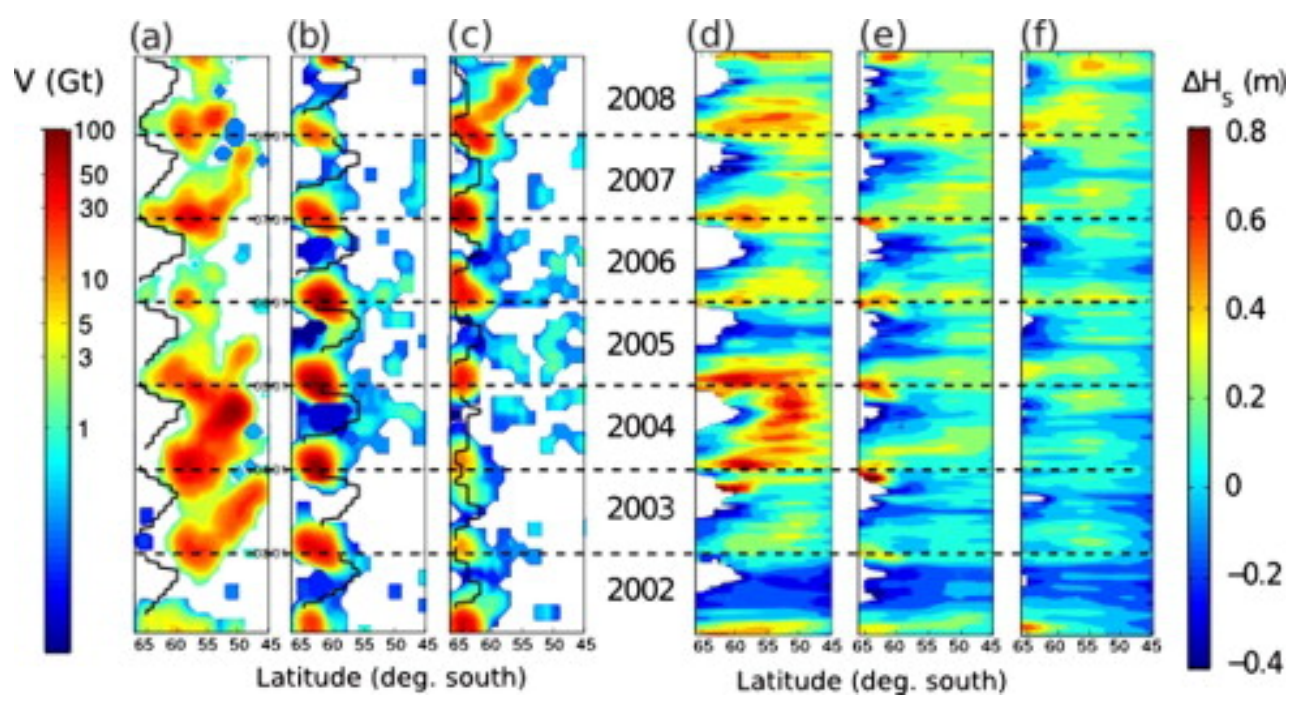


Figure 5

Impact of iceberg in model errors for the significant wave height $H_{s}$. The top panel shows the model normalized root mean square error against altimeter measurements of $H_{s}$, for the year 2008. This is similar to Fig. 11 in Ardhuin et al. (2010). The middle panel show the same error measure for a model that includes a representation of icebergs. Contours are drawn for $7.5 \%$, $10 \%, 12.5 \%, 15 \%$ and $20 \%$ error levels. The bottom panel show the maximum difference, in meters, over the year 2008, between modeled wave heights without $\left(H s_{1}\right)$ and with $\left(H s_{2}\right)$ icebergs.
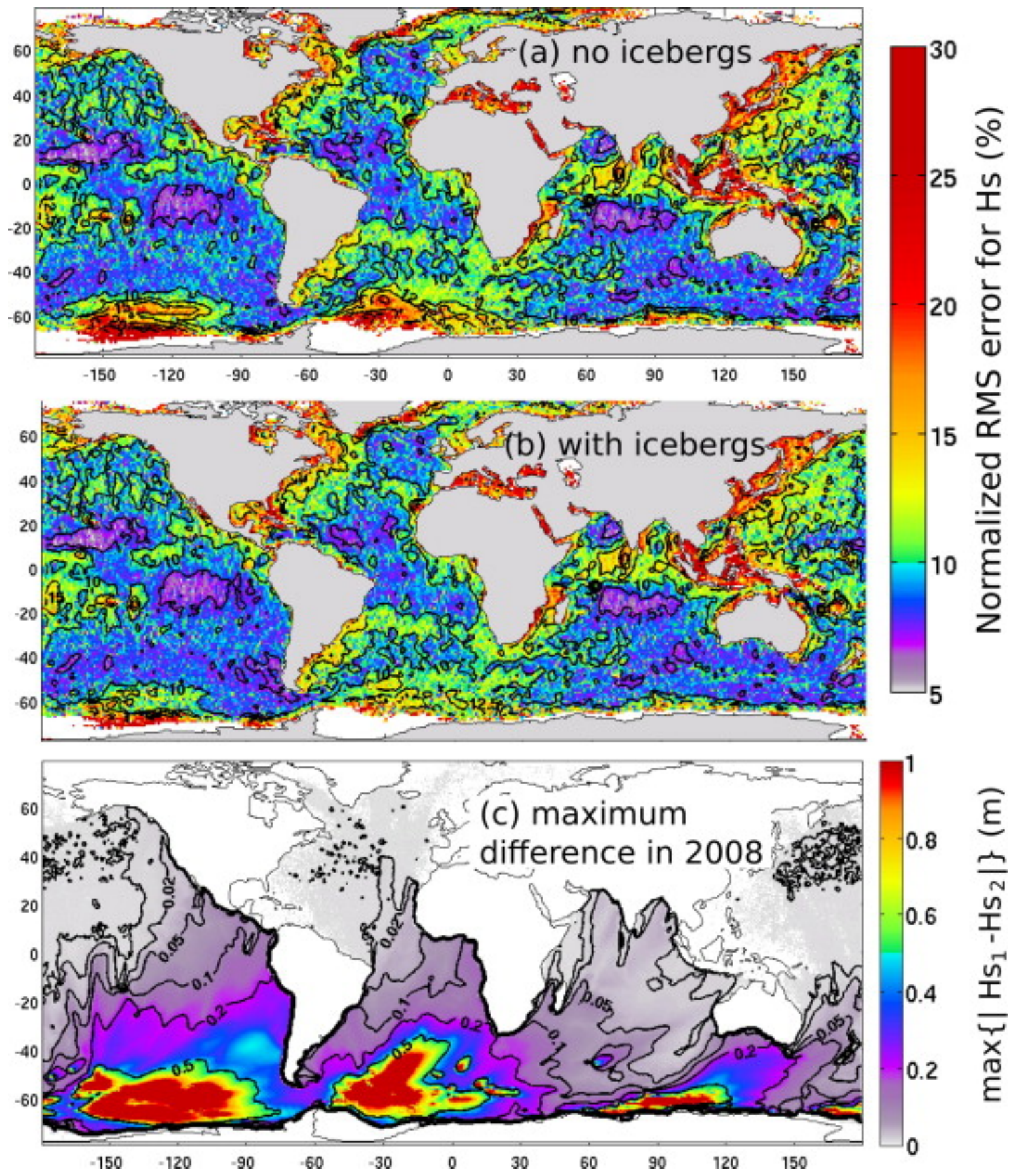


\section{Figure 6}

Bias of modeled significant wave heights relative to satellite altimeter measurements without (left) and with (right) iceberg parameterization, for strips of ocean with a $2^{\circ}$ width in longitude and extending from $65^{\circ} \mathrm{S}$ to $45^{\circ} \mathrm{S}$. The processing is identical to what was done to obtain Fig. 3(c), with the addition of the year 2009 for which iceberg data was processed from Jason-2 and without the year 2002 for which the wave model is less accurate due to less accurate wind fields.

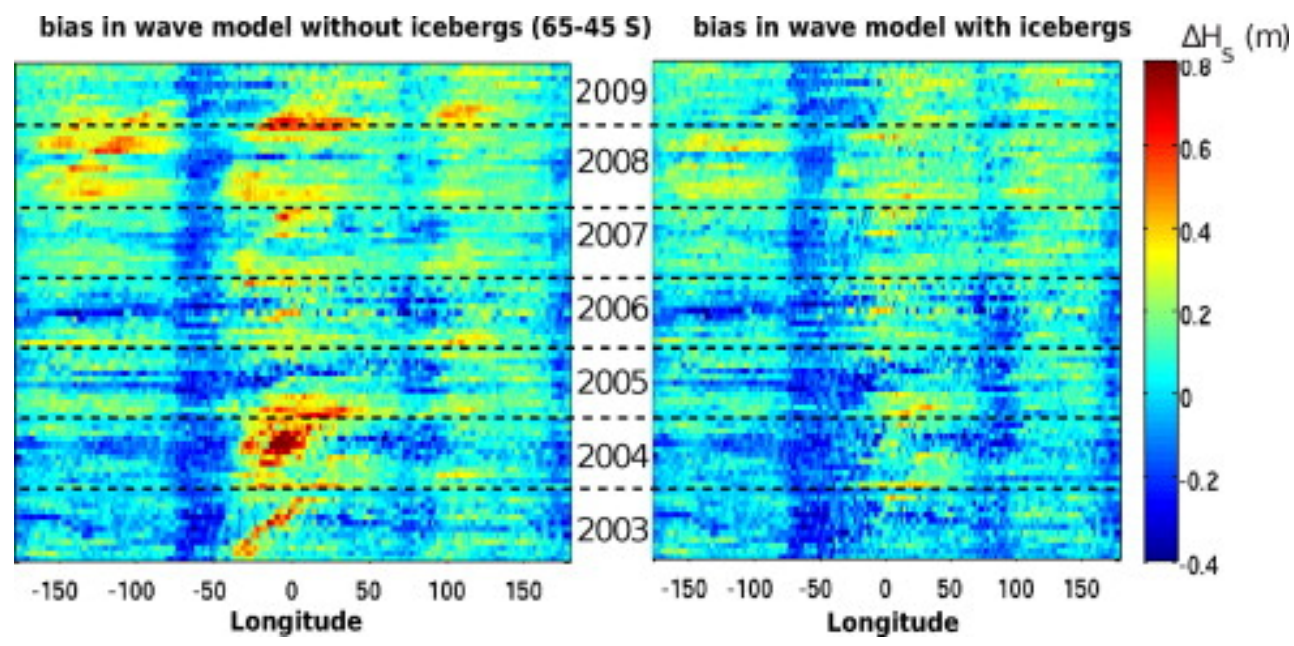

